Bond University

Research Repository

\title{
Comparison of Preseason and In-Season Practice and Game Loads in National Collegiate Athletic Association Division i Football Players
}

\author{
Wellman, Aaron D; Coad, Sam C; Flynn, Patrick J; Siam, Ty K; McLellan, Christopher P \\ Published in: \\ Journal of Strength and Conditioning Research
}

DOI:

10.1519/JSC.0000000000002173

Licence:
Other

Link to output in Bond University research repository.

Recommended citation(APA):

Wellman, A. D., Coad, S. C., Flynn, P. J., Siam, T. K., \& McLellan, C. P. (2019). Comparison of Preseason and In-Season Practice and Game Loads in National Collegiate Athletic Association Division i Football Players. Journal of Strength and Conditioning Research, 33(4), 1020-1027. https://doi.org/10.1519/JSC.0000000000002173

\section{General rights}

Copyright and moral rights for the publications made accessible in the public portal are retained by the authors and/or other copyright owners and it is a condition of accessing publications that users recognise and abide by the legal requirements associated with these rights.

For more information, or if you believe that this document breaches copyright, please contact the Bond University research repository coordinator. 
Authors:

Aaron D. Wellman', Sam C. Coad ${ }^{1}$, Patrick J. Flynn², Ty K. Siam³ ${ }^{3}$, Christopher P. McLellan ${ }^{1}$

${ }^{1}$ Faculty of Health Sciences and Medicine, Bond University, Queensland, Australia.

${ }^{2}$ School of Computer Science and Engineering, University of Notre Dame, Notre Dame, IN.

${ }^{3}$ Football Operations Analyst, New York Giants, East Rutherford, NJ.

Running Head: Comparison of Pre-Season and In-Season Practice and Game Loads Word Count (Abstract): 246

Word Count (Manuscript): 4531

Tables: 3 
References: 30

\section{ABSTRACT}

The aim of the present study was to quantify the individual practice and game loads throughout an NCAA division I football season to determine if significant differences exist between the practice loads associated with pre-season training camp and those undertaken during the in-season period. Thirty-one NCAA division I football players were monitored using GPS and IA (MinimaxX S5; Catapult Innovations, Melbourne, Australia) during 22 pre-season practices, 36 in-season practices, and 12 competitions. The season was divided into four distinct phases for data analysis: pre-season week 1 (pre-season1), pre-season week 2 (pre-season2), pre-season week 3 (pre-season3), and 12 in-season weeks. Individual IA datasets represented players from every offensive and defensive position group (WR: $n=5),(O L: n=4),(R B: n=4),(Q B: n=2),(T E$ : $n=3),(D L: n=4),(L B: n=4),(D B: n=5)$. Data were set at the practice level, where an observation for each player's maximum player load (PLMax) or mean player load (PLMean) from each training camp phase was referenced against each player's respective PL from each game, Tuesday, Wednesday, or Thursday practice session. Notable results included significantly $(p<0.05)$ greater PLMax values attributed to preseason1 compared to PL resulting from all in-season practices, and significantly $(p<0.05)$ higher cumulative PL reported for pre-season1, 2, and 3 compared to every inseason week. Data from the present study augment our understanding of the practice demands experienced by NCAA division I college football players, and provide scope 
for the improvement of pre-season practice design and physical conditioning strategies for coaches seeking to optimize performance.

Key Words: Integrated Accelerometers, monitoring, American football

\section{INTRODUCTION}

American football is a full-contact team sport characterized by high-speed running and frequent accelerations, decelerations, change of direction specific impacts, and blunt force trauma resulting from repeated contact with opponents and the ground during blocking, tackling, and ball carrying $(27,28,29)$. Recent studies $(28,29)$ have provided novel insight to the positional movement demands associated with NCAA division I football, including the quantification of sprint distances and high-intensity accelerations and decelerations, and the frequency and intensity of positional impacts and rapid changes of direction associated with competition. Global positioning system (GPS) derived positional movement demands of NCAA division I football players during competition (28) and pre-season training camp (7) have been reported, however data describing the daily physical demands of the in-season period in college football, remain unestablished.

Global positioning systems technology with integrated triaxial accelerometers (IA) have provided a means of quantifying the physical demands of training and competition in contact team sports $(10,21,28)$. Improvements in technology and sampling methodologies have increased the accuracy of data recorded via portable GPS and IA 
for applied research purposes (17), and have provided a valid and reliable means of assessing activity profiles in team sports $(5,18)$. Additionally, IA have demonstrated reliability (2) as a means of measuring physical activity across multiple players in team sports, with strong inter-unit relationships $(r=0.996-0.999)$ demonstrated during highintensity contact team sport activity.

College football teams generally participate in an intensified pre-season training camp that typically consists of a maximum of 29 practice sessions performed over a period of approximately 4-5 weeks prior to the first competitive event of the season (24). Preseason training camp traditionally involves programming loads that are developed to maximize positive physical adaptation and minimize maladaptation that may be associated with acute and cumulative fatigue, presenting logistical and player management challenges for coaches and performance staff. Despite an increased understanding of the positional movement demands associated with competition and pre-season training camp practices, the daily physical demands associated with practices during the in-season competitive period remain unknown. A more comprehensive understanding of the daily physical demands associated with the inseason competitive period will augment our understanding of the demands of NCAA football players and provide scope for improvements in the planning of pre-season training camp practices to adequately prepare players for the demands of the in-season period. The aim of the present study was to quantify the individual practice and game loads throughout an NCAA division I football season to determine if significant differences exist between the training loads associated with pre-season training camp 
and those undertaken during the in-season competitive period. We hypothesize that there will be significant differences in training loads associated with pre-season training camp when compared to the in-season competitive period in NCAA division I football players.

\section{METHODS}

\section{EXPERIMENTAL APPROACH TO THE PROBLEM}

To examine practice session training loads during the in-season and pre-season periods of an NCAA division I football season, portable IA data were collected from players during 22 pre-season training camp practices, 36 regular season practices, and 12 competitions, completed between August 7 and November 28. The individual IA datasets in the present study represented subjects from all offensive and defensive position groups as follows: (WR: $n=5),(O L: n=4),(R B: n=4),(Q B: n=2),(T E: n=3),(D L:$ $n=4),(L B: n=4),(D B: n=5)$. To determine inter-week PL differentials, each practice and game completed was assessed as a single observation.

\section{SUBJECTS}

Thirty-one National Collegiate Athletic Association (NCAA) Division I Football Bowl Subdivision (FBS) football players (age $20.5 \pm 1.1$ years; age range 18.6-22.9; height $187.6 \pm 6.2 \mathrm{~cm}$; and mass $106.8 \pm 18.6 \mathrm{~kg}$ ) participated in the present study. All 
subjects were collegiate athletes whom had been selected to participate in the football program prior to the commencement of the study. All participants in the present study completed the teams' 8-week summer off-season physical development training program that included a full-body strength and power training program and specific skills and conditioning sessions designed to simulate the demands of NCAA division I college football practice. The present study comprises the statistical analysis of data collected as part of the day to day student athlete monitoring and testing procedures within the university's football program. Ethical approval was obtained from the university's Institutional Review Board and all subjects signed an institutionally approved informed consent document prior to participating in the study.

\section{PROCEDURES}

Global Positioning System Units. Positional movement data were collected from 22 preseason practice sessions, 36 in-season practice sessions and 12 games using commercially available microtechnology units (MinimaxX S5; Catapult Innovations, Melbourne, Australia). The units included a triaxial accelerometer (IA) which operated at $100 \mathrm{~Hz}$ and assessed the frequency and magnitude of full-body acceleration $\left(m \cdot\right.$ second $\left.^{-2}\right)$ in three dimensions, namely, anterior-posterior, mediolateral, and vertical $(19,20)$. Prior to the commencement of each practice and game, GPS receivers were placed outside for 15 minutes to acquire a satellite signal, after which, receivers were placed in a custom designed pocket attached to the shoulder pads of the subjects.

Shoulder pads were custom-fit for each individual, thereby minimizing movement of the 
pads during practices. The GPS and IA receivers used in the present study were positioned in the center of the upper back, slightly superior to the scapulae. Subjects were outfitted with the same GPS receiver for each practice and game. Following the completion of practices, GPS receivers were removed from the shoulder pads, and subsequently downloaded to a computer for analysis utilizing commercially available software (Catapult Sprint 5.1, Catapult Innovations, Melbourne, Australia). In the present study, training load was determined via combined tri-axial accelerometer data and represented as PlayerLoad ${ }^{\mathrm{TM}}(\mathrm{PL})$, which is a modified vector magnitude expressed as the square root of the sum of the squared instantaneous rates of change in acceleration in each of the three planes and divided by 100 (2). Previous research has documented a strong correlation between PL and total distance in Australian football ( $r$ $=0.97,95 \% \mathrm{Cl}: 0.96-0.98)(12)$. Boyd and colleagues (2) have demonstrated the laboratory intra-unit (0.91-1.05\% coefficient of variation [CV]) and inter-unit (1.02-1.10 $\% \mathrm{CV}$ ) reliability of PL and determined its inter-unit reliability in Australian Rules Football matches $(1.90 \% \mathrm{CV})$. Findings from other team sports including basketball, netball, and Australian football have demonstrated the ability of accelerometer derived PL to differentiate between competitive games, scrimmage games, practice drills, positional demands, and levels of competition $(1,3,22)$. The GPS and IA units utilized in the present study have demonstrated the ability to accurately detect collisions associated with contact team-sport participation $(9,15)$. Collision events identified by microtechnology devices during rugby league match-play demonstrated a strong positive correlation with video coded collision events $(r=0.96)$, with no difference between the number of collisions identified by microtechnology and video coding, and 
were sensitive to detect $97.6 \%$ of collisions that occurred (15). Previous research by Gabbett et. al. (9) has also demonstrated the ability of the GPS and IA units utilized in the present study to accurately identify collision events against video-based coding of actual collision events $(r=0.96, p<0.01)$.

Phases of Season. For data analysis, the season was divided into four distinctive phases, namely pre-season week 1 (pre-season1), pre-season week 2 (pre-season2), pre-season week 3 (pre-season3), and 12 in-season weeks. Each week was represented as seven calendar days, and the number of practice sessions included for each pre-season practice week included: 8 for pre-season1 (3 full pads, 3 shoulder pads and helmet, 2 helmets only), 8 for pre-season2 ( 6 full pads and 2 shoulder pads and helmets), and 6 for pre-season3 ( 6 full pads). Two practices occurred on three separate days, namely days 6,8 , and 13 of pre-season training camp. Each in-season week consisted of a Tuesday, Wednesday, and a Thursday practice session, in addition to a game each Saturday.

\section{STATISTICAL ANALYSES}

The present study quantifies the relative PL differential in NCAA division I college football players between three phases of training camp, in-season games, and Tuesday, Wednesday, and Thursday practice sessions. Data were set at the practice level, where an observation for each player's maximum player load (PLMax) session from each training camp phase, or the mean player load (PLMean) across each training 
camp phase, was referenced against each player's respective PL resulting from each game, and Tuesday, Wednesday, or Thursday practice session, for each week throughout the season. Additionally, a model was run examining the cumulative PL for each week from pre-season 1 through the end of the competitive season. Nine OLS regressions, utilizing a control for each individual player, were used to determine the roster-level variation for in-season practices and games compared to each phase of training camp. Each model examined the in-season PL from a Tuesday, Wednesday, Thursday, or Game session against either the maximum player load achieved in each of the three phases of training camp, or the average player load across all sessions from each phase of training camp. Standard errors were clustered at the individual level due to the nested structure of the data throughout the season. Following completion of the regressions, post-hoc t-tests and pair-wise comparisons were used to establish interweek significance for PL variation. Adjusted means for each training camp phase and in-season week are reported for each model in tables 1 and 2. Alpha intervals for all hypothesis testing were set at $p<0.05$ as the level of significance for statistical tests. All statistical analyses were performed using Stata Statistical/Data Analysis Software (Stata 14 for Windows, version 14.1; StataCorp, College Station, TX, USA).

The inclusion criteria for the Tuesday, Wednesday, and Thursday models was full participation in a session, thus all observations where a player participated fully were used. In the case of unit malfunctions where an individual participated fully, player load was imputed for individuals based on their unique average for that type of session, which occurred on seven instances throughout the study. The inclusion criteria for the 
game day model was participation in $\geq 75 \%$ of the offensive or defensive plays, while the inclusion criteria for the cumulative PL model was full participation in all sessions in that given week. Thirty-one players were eligible for the present study.

\section{RESULTS}

Several significant differences in PLMax (Table 1) and PLMean (Table 2) between preseason training camp practices and in-season practice sessions were reported.

Maximum and Mean PL were significantly $(\mathrm{p}<0.05)$ lower in pre-season2 and preseason3 compared to pre-season1. Every in-season Tuesday practice session resulted in significantly $(p<0.05)$ lower PL than the PLMax achieved in pre-season1. Additionally, Tuesday practice sessions in weeks 1-3 and 9-12 demonstrated significantly $(p<0.05)$ lower PL than the PLMax reported in pre-season2 and preseason3. Wednesday and Thursday practices from every in-season week, except inseason week 5 , resulted in significantly $(p<0.05)$ lower PL than the PLMax demonstrated in pre-season 1, 2, and 3. Five games exhibited significantly $(p<0.05)$ lower PL than the PLMax reported in pre-season1, one game resulted in significantly $(p<0.05)$ higher PL than the PLMax in pre-season1, while the remaining 6 games demonstrated no significant $(\mathrm{p}<0.05)$ differences than the PLMax in pre-season1.

(1)


An examination of PLMean resulting from pre-season training camp demonstrated significantly $(p<0.05)$ greater PLMean in pre-season1 than all in-season Wednesday and Thursday practice sessions, and 9 out of 12 Tuesday practice sessions. The inseason week 1 Tuesday practice session PL was significantly $(p<0.05)$ lower than the PLMean in pre-season1, 2 and 3, while Tuesday practice sessions in weeks 2-8 demonstrated significantly $(p<0.05)$ higher PL than the PLMean reported in pre-season2 and 3. No significant $(p<0.05)$ differences were established between Tuesday practice sessions in weeks 9-12 and those demonstrated in pre-season2 and 3. Four in-season Wednesday practices resulted in significantly $(p<0.05)$ higher PL than PLMean in preseason2, while another four Wednesday practices resulted in significantly $(p<0.05)$ lower PL than the PLMean in pre-season2. All Thursday practice sessions were associated with significantly $(p<0.05)$ lower PL than the PLMean reported for preseason2 and 3. Ten out of twelve games resulted in significantly $(p<0.05)$ higher PL than the PLMean demonstrated in pre-season1, while all games were associated with significantly $(p<0.05)$ higher PL than the PLMean achieved in pre-season2 and 3.

The cumulative PL (Table 2) resulting from pre-season1 was significantly $(p<0.05)$ greater than that of pre-season2 and 3, and the cumulative PL in pre-season2 was significantly greater than that of pre-season3. All pre-season weeks demonstrated significantly $(p<0.05)$ higher cumulative PL than the cumulative PL resulting from all 12 in-season weeks. 
The average and maximum session duration for pre-season1, pre-season2, pre-

season3, Tuesday, Wednesday, and Thursday practice sessions, in addition to average and maximum game durations, are described in Table 3.

\section{DISCUSSION}

The aim of the present study was to quantify the individual practice and game loads throughout an NCAA division I football season to determine if significant differences exist between the training loads associated with pre-season training camp and those undertaken during the in-season competitive period. The results of the present study contribute novel insight into the practice and competitive loads experienced by NCAA division I college football players throughout the pre-season and in-season periods, and provide scope for the programming of pre-season practices and the design of physical conditioning strategies to prepare athletes for the rigors of pre-season training camp. The results confirm our hypothesis that significant differences in training loads associated with pre-season training camp, when compared to the in-season competitive period in NCAA division I football players, exist. The most notable findings were the significantly $(p<0.05)$ greater PLMax values attributed to pre-season1 compared to PL resulting from all in-season practices, and the significantly $(p<0.05)$ higher cumulative 
PL reported for pre-season1, 2, and 3 compared to the cumulative PL for every inseason week.

In the present study, pre-season1 resulted in significantly $(P<0.05)$ higher PLMax and PLMean values than both pre-season2 and pre-season3. The PLMax achieved in the first week of pre-season camp was significantly $(p<0.05)$ higher than the $P L$ resulting from $42 \%$ of games, and all Tuesday, Wednesday, and Thursday practice sessions throughout the in-season period. The PLMean resulting from pre-season1 was significantly $(p<0.05)$ higher than PL values of all Wednesday and Thursday practices, nine of twelve Tuesday practice sessions, and two games. These data clearly demonstrate that pre-season 1 exposed players to the highest PL of the pre-season and in-season practice period, in addition to significantly $(\mathrm{p}<0.05)$ higher $\mathrm{PL}$ than 5 out of 12 games. Indeed, only one game was associated with a significantly $(p<0.05)$ higher PL than the PLMax achieved in pre-season1. Collectively, these data contrast training load progression recommendations provided to mitigate injury risk (16) and optimize athlete preparation prior to the commencement of the NCAA division I football season.

It is widely understood that the appropriate planning of single and multi-day pre- and inseason training sessions is a fundamental aspect of optimal performance, however limited data exits to support a specific approach to programming training sessions in team sports (23). Comparing the results of the present study with previous examinations is problematic due to the lack of similar investigations in NCAA division I football. Previous investigations in Australian football have reported increased training 
loads and training session duration in the pre-season period when compared to the inseason competitive period $(23,26)$. While similarities may exist between Australian football and NCAA division I college football, direct comparisons between the preseason periods in each of these sports is problematic, most notably due to the duration of the pre-season period in Australian football, often lasting more than 20 weeks (23), while college football pre-season practice takes place over approximately four weeks. In NCAA division I college football, GPS-derived positional movement characteristics have been quantified $(7,28)$, and biochemical markers of muscle damage associated with pre-season training camp have been examined $(8,14)$. However, research has not attempted to quantify the differences that may exist between practice loads encountered by NCAA division I football players during pre-season training camp with those experienced during the in-season period, and previously this information was limited to coaching intuition and anecdotal reports. It is clear that pre-season training camp is a critical period for football players, yet recommendations have not been established which elucidate effective strategies for periodizing pre-season training camp practices to maximize the position-specific tactical, technical, and physical demands while minimizing the deleterious effects of fatigue. Periodization refers to the logical and systematic process of sequencing and integrating training interventions to achieve peak performance at the appropriate times (13). An ideology that highlights the influence of a properly periodized period of training is referred to as the stimulus-fatigue-recoveryadaptation theory, which suggests that the greater the overall magnitude of the physical demands, the more fatigue accumulates, and the longer the recovery and adaptation process takes (13). When comparing in-season to pre-season practice demands, it is 
reasonable to suggest that the fatigue associated with pre-season training camp practices in the present study may require increased time recover from, and adapt to, the imposed demands.

In the present study, an in-season week of training consisted of 3 practices and 1 game, while pre-season 1 was comprised of 8 practice sessions in the first 7 days, and as such, the cumulative training load resulting from pre-season 1 is increased compared to a typical in-season week of training. This however, does not explain the significantly $(p<0.05)$ greater PLMean and PLMax reported for individual practice sessions of preseason1, which was likely the result of not only the composition, but the duration of the practice sessions. A greater portion of practice time in pre-season1 was devoted to position-specific skills and techniques than on situational and tactical planning in an offensive or defensive group setting, which commonly occurs throughout in-season practice sessions when preparing for competition. Individual skill work takes place in smaller groups, and allows for increased frequency of movement, potentially resulting in higher PL. The mean session duration in pre-season1 was 145 minutes, however the first practice session of pre-season1 was 169 minutes in duration, which represented the longest practice session of the entire season. The significant increases in PLMax and PLMean that occurred during pre-season1 may therefore be also attributed to practice session duration. Previous research (26) in Australian football has demonstrated that reductions in session duration accompany similar reductions in PL. Specifically, a $30 \%$ reduction in duration resulted in a $~ 30 \%$ reduction in $\mathrm{PL}$, and as such, periodizing practice duration may be an effective strategy to reduce $\mathrm{PL}$ and 
facilitate between-session recovery to reduce injury risk and optimize subsequent practice session performance.

The PLMax and PLMean values reported in pre-season2 were not significantly different than pre-season3, however a significant $(p<0.05)$ decrease in both PL measures was demonstrated compared to pre-season1. Week 2 of pre-season consisted of 8 practice sessions with an average practice session duration of 123 minutes. Practice sessions in pre-season2 were programmed to provide less time dedicated to individual positionspecific skill work and a larger amount of time to periods of situational drills involving the entire offensive and defensive teams. During the in-season period, the Tuesday practice sessions were planned as the highest practice loads of the week, and PL resulting from in-season Tuesday practices were significantly $(p<0.05)$ greater than PLMean in pre-season2 for weeks $2-8$ during the in-season period. The PL associated with the Tuesday practice session for in-season week 1 was significantly $(p<0.05)$ lower than the PLMean in pre-season2, the likely result of a reduction in session duration in attempt to mitigate any deleterious effects of fatigue accumulated in pre-season training camp. A similar pattern was demonstrated for Wednesday practice sessions whereby in-season week $1,10,11$, and 12 demonstrated significantly $(p<0.05)$ lower PL than the PLMean reported in pre-season2. These findings illustrate that coaches may intuitively reduce practice loads during in-season, particularly in the latter part, to maintain the physical capacities developed throughout the pre-season and early in-season periods, but to also provide adequate recovery to support optimal gameday performance. 
A comparison of PLMean from pre-season3 practice sessions with PL resulting from inseason Tuesday and Wednesday practice sessions reveals a decrease in training loads for weeks 9-12 of the season. This appears to be the result of a pre-planned reduction in session duration for Tuesday and Wednesday practices the last four weeks of the season. Similar reductions in PL associated with Thursday practices sessions for the last 4 weeks of the season were not demonstrated, most likely due to the consistent nature of load programming for Thursday practice sessions

An examination of the cumulative weekly PL revealed significantly $(p<0.05)$ greater cumulative PL for pre-season1 than pre-season2 and 3, and significantly $(p<0.05)$ greater cumulative PL for pre-season2 than pre-season3. Additionally, all pre-season weeks were associated with significantly $(p<0.05)$ greater cumulative PL than all inseason weeks. The significantly $(p<0.05)$ increased cumulative workloads demonstrated in pre-season training camp most likely resulted from the increased number of practices when compared to a typical in-season week. However, along with the increased session frequency associated with pre-season training camp, the workloads, particularly in pre-season1, were also significantly $(p<0.05)$ greater than Tuesday, Wednesday, and Thursday in-season practice sessions. Additionally, only one game demonstrated a significantly $(p<0.05)$ higher PL than the PLMax achieved in pre-season1. While the PLMax achieved in pre-season1 is comparable to the PL which may be experienced by NCAA division I football players during competition, it is reasonable to question the appropriateness of this particular loading scheme for week 1 
of pre-season training camp, particularly in light of previous research demonstrating increased risk of injury and illness associated with acute spikes in training load indicative of pre-season training camp $(16,25)$.

American football is associated with high levels of physicality, and as such, practice sessions require adequate intensity to prepare for competitive demands. To improve the likelihood for success, coaches regularly plan practice sessions which challenge the barriers of what players can achieve without exceeding individual training tolerance capacity (25). The present study demonstrated significantly $(p<0.05)$ higher workloads in pre-season 1 than any other phase of pre-season camp, and although the optimal preseason practice session training load required to produce favorable physical adaptations and mitigate undesirable consequences associated with excessive fatigue has not been established, improvements in load programming may prove advantageous. Research in similar collision-based team sport (16) has demonstrated unfavorable outcomes associated with acute increases in training loads commonly seen in the first week of pre-season practice in NCAA division I football players. An examination (16) of the ratio of acute workload, represented as total distance accumulated over 7 days, compared to chronic workloads, calculated as the 4-week rolling average acute workload, was found to be predictive of injury in rugby league. Specifically, when players were subjected to an acute 7-day workload that was classified as $\sim$ twofold greater than the workload in which they were accustomed to, up to a 10-fold increase in injury occurred. Piggott et. al (25) demonstrated acute spikes in weekly training load (>10\%) accounted for $\sim 40 \%$ of illness and injury in the subsequent 
7-day period in Australian footballers. Colby et. al. (4) reported 3-weekly workloads to have the strongest relationship with intrinsic injury incidence in the pre-season and inseason period. Large week-to-week changes in training load also increased the risk of injury in professional rugby players (6). However, increased participation in pre-season practices may reduce the likelihood of injury during the in-season period, presumably by allowing players to accumulate high chronic workloads (16), and perhaps by identifying players who are able to handle higher pre-season training loads and therefore are more robust to injury (30). Performance coaches must have a clear understanding of the planned practice loads associated with pre-season training camp, particularly within the first week, and tailor the preceding weekly conditioning loads leading up to training camp, accordingly. A collaborative approach to pre-season training camp should be implemented, whereby the coaching staff, performance staff, and the medical staff work jointly to develop appropriate loading protocols prior to, and during pre-season training camp, which serve to improve the sport-specific physical capacities but avoid the abrupt increases in PL which have been associated with injury and illness.

The results of the present study provide novel insight into the contrasting physical demands of NCAA division I football players between the pre-season, particularly in preseason1, and in-season periods. The findings of the study may seem intuitive to those intimately involved in NCAA division I football, however this is the first investigation to elucidate these suspicions objectively. Despite the novel findings, these data represent one team competing in NCAA division I college football, and consequently, the findings may be limited to this specific team and the philosophy of this particular coaching staff. 
PRACTICAL APPLICATIONS

444

The results confirm our hypothesis that significant differences in training loads associated with pre-season training camp, when compared to the in-season competitive period in NCAA division I football players, exist. The most notable findings were the significantly $(p<0.05)$ greater PLMax values attributed to pre-season1 compared to $P L$ resulting from all in-season practices, and the significantly $(p<0.05)$ higher cumulative PL reported for pre-season1, 2, and 3 compared to every in-season week. Data from the present study augment our understanding of the practice demands experienced by NCAA division I college football players, and provide scope for the improvement of preseason practice design and physical conditioning strategies for coaches seeking to optimize performance.

The commencement of the competitive season in college football is highly anticipated by players and coaches alike, and as such, may result in excessive programming of practice volumes and intensities, particularly in pre-season1. An examination (11) in rugby league demonstrated that reductions in pre-season training load, via decreases in session duration, resulted in decreased rates of injury, without negatively impacting improvements in physical fitness. Similar investigations in NCAA football have not been undertaken, however a more deliberate increase in training load, resulting from calculated increases in session duration may be warranted. Purposeful planning of preseason training camp practices requires collaboration between the sport coaches, performance staff, and medical staff. Limiting the practice session duration, particularly 
465 for the initial practices, and throughout first week of pre-season, may prove to be

466

467

468

469

470

471

472

473

474

475

476

477

478

479

480

481 worthwhile.

For many NCAA football teams, the first week of pre-season camp represents an acute, and often times, significant increase in training load. Coaches seeking to maximize performance and minimize the negative effects of fatigue should make efforts to lessen these acute increases by tightly controlling factors contributing to increases in training load in pre-season1, and by ensuring athletes are accustomed to these loads prior to the start of pre-season camp. This may be accomplished by limiting the duration of the first pre-season training camp practice, followed by gradual increases in session duration throughout pre-season1. Additionally, performance coaches should program physical conditioning loads in the weeks leading up to pre-season training camp, that approximate the physical movement demands of pre-season practice sessions. Collectively, these measures may assist in ensuring that the first week of pre-season training camp represents a $\leq 10 \%$ increase in training load, and may reduce the likelihood of maladaptation associated with excessive fatigue and under-recovery.

Future studies should examine how coaches seeking to enhance performance, can manipulate pre-season practice loads, at the team, position, and individual level, to mitigate fatigue, enhance recovery, and optimize game-day performance. 
489

490

491

492

493

494

495

496

497

498

499

500

501

502

503

504

505

506

507

508

509

510

\section{ACKNOWLEDGEMENTS}

No grant aid or manufacturer's aid was received in conjunction with the present study, and no conflicts of interest are declared. The results of this study do not constitute endorsement of the product by the authors of the National Strength and Conditioning Association.

\section{REFERENCES}

1. Boyd, LJ, Ball, K, and Aughey, RJ. Quantifying external load in Australian football matches and training using accelerometers. Int J Sports Physiol Perform 8: 44-51, 2013.

2. Boyd, LJ, Ball, K, and Aughey, RJ. The reliability of minimaxx accelerometers for measuring physical activity in Australian football. Int J Sports Physiol Perform 6: $311-321,2011$.

3. Chandler, PT, Pinder, SJ, Curran, JD, and Gabbett, TJ. Physical demands of training and competition in collegiate netball players. J Strength Cond Res 28: 2732-2737, 2014.

4. Colby, MJ, Dawson, B, Heasman, J, Rogalski, B, and Gabbett, TJ. Accelerometer and gps-derived running loads and injury risk in Australian footballers. J Strength Cond Res 28: 2244-2252, 2014.

5. Coutts, AJ, and Duffield, R. Validity and reliability of GPS devices for measuring movement demands of team sports. J Sci Med Sport 13: 133-135, 2010. 
6. Cross, MJ, Williams, S, Trewartha, G, Kemp, SP, and Stokes, KA. The influence of in-season training loads on injury risk in professional rugby union. Int J Sports Physiol Perform 11: 350-355.

7. DeMartini, JK, Martschinske, JL, Casa, DJ, Lopez, RM, Ganio, MS, Walz, SM, and Coris, EE. Physical demands of National Collegiate Athletic Association division I football players during preseason training in the heat. J Strength Cond Res 25: 2935-2943, 2011.

8. Ehlers, GG, Ball, TE, and Liston, L. Creatine kinase levels are elevated during 2-aday practices in collegiate football players. J Athl Train 37: 151-156, 2002.

9. Gabbett, TJ, Jenkins, DG, and Abernathy, B. Physical collisions and injury during professional rugby league skills training. J Sci Med Sport 13: 578-583, 2010.

10. Gabbett, TJ, Jenkins, DG, and Abernethy, B. Physical demands of professional rugby league training and competition using microtechnology. J Sci Med Sport 15: 80-86, 2012.

11. Gabbett, TJ. Reductions in pre-season training loads reduce training injury rates in rugby league players. Br J Sports Med 38: 743-749, 2004.

12. Gallo, T, Cormack, S, Gabbett, T, Williams, M, and Lorenzen, C. Characteristics impacting on session rating of perceived exertion training load in Australian footballers. J Sports Sci 33: 467-475, 2015.

13. Haff, $G$ and Triplett, $T$ (Eds) (2016). Essentials of strength training and conditioning, fourth edition. Champaign, IL: Human Kinetics. 
532

533

534

535

536

537

538

539

540

14. Hoffman, JR, Kang, J, Ratamess, NA, and Faigenbaum, AD. Biochemical and hormonal responses during an intercollegiate football season. Med Sci Sports Exerc 37: 1237-1241.

15. Hulin, BT, Gabbett, TJ, Johnston, RD, and Jenkins, DG. Wearable microtechnology can accurately identify collision events during professional rugby league matchplay. J Sci Med Sport 20: 638-642, 2017.

16. Hulin, BT, Gabbett, TJ, Lawson, DW, Caputi, P, and Sampson, JA. The acute:chronic workload ratio predicts injury: high chronic workload may decrease injury risk in elite rugby league players. Br J Sports Med 50: 231-236, 2016.

17. Johnston, RD, Gabbett, TJ, and Jenkins, DG. Applied sports science of Rugby League. Sports Med 44: 1087-1100, 2014.

18. Johnston, RD, Watsford, ML, Kelly, SJ, Pine, MJ, and Spurrs, RW. Validity and interunit reliability of $10 \mathrm{hz}$ and $15 \mathrm{hz}$ units for assessing athlete movement demands. J Strength Cond Res 28: 1649-1655, 2014.

19. Krasnoff, JB, Kohn, MA, Choy, FKK, Doyle, J, Johansen, K, and Painter, PL. Interunit and intraunit reliability of the RT3 triaxial accelerometer. J Phys Act Health 5: 527-538, 2008.

20. McLellan, CP, Lovell, DI, and Gass, GC. Biochemical and endocrine responses to impact and collision during elite Rugby League match play. J Strength Cond Res 25: 1553-1562, 2011.

21. McLellan, CP, Lovell, DI, and Gass, GC. Performance analysis of elite rugby league match play using global positioning systems. J Strength Cond Res 25: 1703-1710, 2011. 
22. Montgomery, PG, Pyne, DB, and Minahan, CL. The physical and physiological demands of basketball training and competition. Int J Sports Physiol Perform 5: 7586, 2010.

23. Moreira, A, Bilsborough, JC, Sullivan, Cj, Ciancosi, M, Aoki, MS, and Coutts, AJ. Training periodization of professional Australian football players during an entire Australian Football League Season. Int J Sports Physiol Perform 10: 566-571, 2015.

24. NCAA Division I manual. Bylaw 17.10: p. 252, 2015-2016.

25. Piggot, B, Newton, MJ, and McGuigan, MR. The relationship between training load and injury and illness over a pre-season at an Australian football league club. $J$ of Aust Strength Cond 17: 4-17, 2009.

26. Ritchie, D, Hopkins, WG, Buchheit, M, Cordy, J, and Bartlett, JD. Quantification of training and competition load across a season in an elite Australian football club. Int J Sports Physiol Perform 11: 474-479, 2016.

27. Sterczala, AJ, Flanagan, SD, Looney, DP, Hooper, DR, Szivak, TK, Comstock, BA, White, MT, Dupont. WH, Martin, GJ, Volek, JS, Maresh, CM, and Kraemer, WK. Similar hormonal stress tissue damage in response to national collegiate athletic association (NCAA) division I football games played in consecutive seasons. $J$ Strength Cond Res 28: 3234-3238, 2014.

28. Wellman, AW, Coad, SC, Goulet, GC, and McLellan, CP. Quantification of competitive game demands of NCAA division I college football players using global positioning systems. J Strength Cond Res 30: 11-19, 2016. 
577 29. Wellman, AW, Coad, SC, Goulet, GC, and McLellan, CP. Quantification of accelerometer derived impacts associated with competitive games in NCAA division I college football players. J Strength Cond Res 31: 330-338, 2017.

30. Windt, J, Gabbett, TJ, Ferris, D, and Khan, KM. Training load-injury paradox: is rugby league players? Br J Sports Med 51: 645-650, 2017. 
Table 1. PLMax Predicted Means. ${ }^{1}$ Significantly different than Pre- $1,{ }^{2}$ Significantly different than Pre- $2,{ }^{3}$ Significantly different than Pre-3. Line 2: Lower and Upper limits of 95\% Confidence Interval

\begin{tabular}{|c|c|c|c|c|}
\hline Seasonal Week & Tuesday & Wednesday & Thursday & Game \\
\hline Pre-Season1 & $\begin{array}{c}\mathbf{5 7 9 . 9} \\
(554.5,605.3)\end{array}$ & $\begin{array}{c}\mathbf{5 7 8 . 8} \\
(554.3,603.2)\end{array}$ & $\begin{array}{c}\mathbf{5 8 1 . 3} \\
(555.5,607.1)\end{array}$ & $\begin{array}{c}\mathbf{5 6 4 . 3} \\
(539.1,589.6)\end{array}$ \\
\hline Pre-Season2 & $\begin{array}{c}460.8^{1} \\
(440.4,481.2)\end{array}$ & $\begin{array}{c}461.0^{1} \\
(442.2,479.7)\end{array}$ & $\begin{array}{c}464.7^{1} \\
(442.5,486.8)\end{array}$ & $\begin{array}{c}446.7^{1} \\
(425.8,467.5)\end{array}$ \\
\hline Pre-Season3 & $\begin{array}{c}442.9^{1} \\
(427.6,458.1) \\
\end{array}$ & $\begin{array}{c}441.7^{1} \\
(426.2,457.2) \\
\end{array}$ & $\begin{array}{c}444.2^{1} \\
(423.7,464.6) \\
\end{array}$ & $\begin{array}{c}427.2^{1} \\
(404.7,449.8)\end{array}$ \\
\hline In-Season 1 & $\begin{array}{c}\mathbf{3 5 3 . 3}^{123} \\
(336.2,370.4)\end{array}$ & $\begin{array}{c}322.0^{123} \\
(306.3,337.7)\end{array}$ & $\begin{array}{c}285.5^{123} \\
(274.2,296.8)\end{array}$ & $\begin{array}{c}\mathbf{5 3 8 . 1}^{23} \\
(493.8,582.4)\end{array}$ \\
\hline In-Season 2 & $\begin{array}{c}406.9^{123} \\
(392.4,421.3)\end{array}$ & $\begin{array}{c}420.4^{123} \\
(405.1,435.8)\end{array}$ & $\begin{array}{c}328.2^{123} \\
(312.0,344.3)\end{array}$ & $\begin{array}{c}567.2^{23} \\
(543.8,590.7)\end{array}$ \\
\hline In-Season 3 & $\begin{array}{c}415.8 \\
(397.6,433.9)\end{array}$ & $\begin{array}{c}395.6^{123} \\
(380.0,411.2)\end{array}$ & $\begin{array}{c}270.0^{123} \\
(245.1,294.9)\end{array}$ & $\begin{array}{c}605.7^{123} \\
(584.0,627.5)\end{array}$ \\
\hline In-Season 4 & $\begin{array}{c}451.3^{1} \\
(436.1,466.5)\end{array}$ & $\begin{array}{c}408.9^{123} \\
(393.4,424.4)\end{array}$ & $\begin{array}{c}307.0^{123} \\
(293.2,320.7)\end{array}$ & $\begin{array}{c}\mathbf{5 2 5 . 5} \\
(498.4,552.7)\end{array}$ \\
\hline In-Season 5 & $\begin{array}{c}477.3^{13} \\
(456.5,498.2)\end{array}$ & $\begin{array}{c}425.6^{12} \\
(407.8,443.5)\end{array}$ & $\begin{array}{c}325.4^{123} \\
(309.0,341.7)\end{array}$ & $\begin{array}{c}\mathbf{5 2 7 . 4} \\
(508.2,546.6)\end{array}$ \\
\hline In-Season 6 & $\begin{array}{c}437.7^{1} \\
(420.0,455.5)\end{array}$ & $\begin{array}{c}408.9^{123} \\
(393.8,423.9)\end{array}$ & $\begin{array}{c}298.6^{123} \\
(286.6,310.5)\end{array}$ & $\begin{array}{c}\mathbf{5 1 4 . 5} \\
(483.2,545.8)\end{array}$ \\
\hline In-Season 7 & $\begin{array}{c}467.1^{1} \\
(440.7,493.6)\end{array}$ & $\begin{array}{c}410.8^{123} \\
(388.5,433.1)\end{array}$ & $\begin{array}{c}308.7^{123} \\
(293.2,324.1)\end{array}$ & $\begin{array}{c}599.3^{23} \\
(567.4,631.3)\end{array}$ \\
\hline In-Season 8 & $\begin{array}{c}\mathbf{4 2 4 . 8} \\
(410.7,438.9)\end{array}$ & $\begin{array}{c}412.5^{123} \\
(397.5,427.5)\end{array}$ & $\begin{array}{c}325.6^{123} \\
(313.0,338.3)\end{array}$ & $\begin{array}{c}447.3^{1} \\
(432.5,462.0)\end{array}$ \\
\hline In-Season 9 & $\begin{array}{c}394.7^{123} \\
(380.8,408.7)\end{array}$ & $\begin{array}{c}391.9^{123} \\
(379.3,404.6)\end{array}$ & $\begin{array}{c}266.5^{123} \\
(254.2,278.8)\end{array}$ & $\begin{array}{c}557.2^{23} \\
(539.2,575.2)\end{array}$ \\
\hline In-Season 10 & $\begin{array}{c}401.3^{123} \\
(381.1,421.5)\end{array}$ & $\begin{array}{c}353.9^{123} \\
(331.8,376.0)\end{array}$ & $\begin{array}{c}\mathbf{3 1 5 . 9} \\
(295.3,336.4)\end{array}$ & $\begin{array}{c}488.3^{13} \\
(455.6,520.9)\end{array}$ \\
\hline In-Season 11 & $\begin{array}{c}381.0 \\
(352.4,409.6)\end{array}$ & $\begin{array}{c}347.6^{123} \\
(326.4,368.7)\end{array}$ & $\begin{array}{c}332.5^{123} \\
(301.5,363.5)\end{array}$ & $\begin{array}{c}\mathbf{5 3 0 . 8} \\
(508.9,552.7)\end{array}$ \\
\hline In-Season 12 & $\begin{array}{c}386.0^{123} \\
(370.1,401.9) \\
\end{array}$ & $\begin{array}{c}357.8^{123} \\
(344.7,371.0) \\
\end{array}$ & $\begin{array}{c}317.6^{123} \\
(302.0,333.1) \\
\end{array}$ & $\begin{array}{c}549.0^{23} \\
(529.7,568.2) \\
\end{array}$ \\
\hline \# of Observations & 422 & 422 & 423 & $* 252$ \\
\hline
\end{tabular}


Table 2. PLMean and Cumulative PL Predicted Means. ${ }^{1}$ Significantly different than Pre- $1,{ }^{2}$ Significantly different than Pre-2, ${ }^{3}$ Significantly different than Pre-3. Line 2: Lower and Upper limits of 95\% Confidence Interval

\begin{tabular}{|c|c|c|c|c|c|}
\hline Seasonal Week & Tuesday & Wednesday & Thursday & Game & $\begin{array}{c}\text { Cumulative Weekly } \\
\text { Player Load }\end{array}$ \\
\hline Pre-Season1 & $\begin{array}{c}466.8 \\
(449.7,484.0)\end{array}$ & $\begin{array}{c}465.7 \\
(450.6,480.8)\end{array}$ & $\begin{array}{c}468.2 \\
(450.6,485.8)\end{array}$ & $\begin{array}{c}453.2 \\
(437.1,469.4)\end{array}$ & $\begin{array}{c}\mathbf{3 7 5 7 . 5} \\
(3611.5,3903.4)\end{array}$ \\
\hline Pre-Season2 & $\begin{array}{c}385.7^{1} \\
(366.9,404.5)\end{array}$ & $\begin{array}{c}385.9^{1} \\
(368.9,403.0)\end{array}$ & $\begin{array}{c}389.6^{1} \\
(371.2,408.0)\end{array}$ & $\begin{array}{c}\mathbf{3 7 3 . 5}^{1} \\
(354.9,392.0)\end{array}$ & $\begin{array}{c}3563.9^{1} \\
(3423.4,3704.3)\end{array}$ \\
\hline Pre-Season3 & $\begin{array}{c}377.1^{1} \\
(363.4,390.8) \\
\end{array}$ & $\begin{array}{c}375.9^{1} \\
(363.8,388.1) \\
\end{array}$ & $\begin{array}{c}\mathbf{3 7 8 . 4} \\
(363.4,393.4) \\
\end{array}$ & $\begin{array}{c}363.5^{1} \\
(342.0,384.9) \\
\end{array}$ & $\begin{array}{c}1937.7^{12} \\
(1861.8,2013.6)\end{array}$ \\
\hline In-Season 1 & $\begin{array}{c}353.8^{123} \\
(337.2,370.4)\end{array}$ & $\begin{array}{c}322.5^{123} \\
(307.3,337.7)\end{array}$ & $\begin{array}{c}286.0^{123} \\
(275.8,296.1)\end{array}$ & $\begin{array}{c}537.6^{123} \\
(493.9,581.4)\end{array}$ & $\begin{array}{c}1412.9^{123} \\
(1352.9,1473.0)\end{array}$ \\
\hline In-Season 2 & $\begin{array}{c}406.8^{123} \\
(392.6,420.9)\end{array}$ & $\begin{array}{c}420.3^{123} \\
(404.9,435.6)\end{array}$ & $\begin{array}{c}328.0^{123} \\
(311.4,344.6)\end{array}$ & $\begin{array}{c}\mathbf{5 6 6 . 5} \\
(541.2,591.8)\end{array}$ & $\begin{array}{c}1572.8^{123} \\
(1514.5,1631.2)\end{array}$ \\
\hline In-Season 3 & $\begin{array}{c}415.7^{123} \\
(397.2,434.4)\end{array}$ & $\begin{array}{c}395.6^{1} \\
(379.8,411.5)\end{array}$ & $\begin{array}{c}270.0 \\
(245.1,294.9)\end{array}$ & $\begin{array}{c}606.5^{123} \\
(583.7,629.3) \\
\end{array}$ & $\begin{array}{c}1518.2^{123} \\
(1451.3,1585.1)\end{array}$ \\
\hline In-Season 4 & $\begin{array}{c}451.7^{23} \\
(436.2,467.2)\end{array}$ & $\begin{array}{c}409.3^{123} \\
(393.9,424.7)\end{array}$ & $\begin{array}{c}307.4^{123} \\
(293.9,320.8)\end{array}$ & $\begin{array}{c}\mathbf{5 2 4 . 4} \\
(498.0,550.8)\end{array}$ & $\begin{array}{c}1642.0^{123} \\
(1576.5,1707.4)\end{array}$ \\
\hline In-Season 5 & $\begin{array}{c}477.7^{23} \\
(456.8,498.6)\end{array}$ & $\begin{array}{c}426.0 \\
(407.9,444.1)\end{array}$ & $\begin{array}{c}325.8^{123} \\
(309.4,342.2)\end{array}$ & $\begin{array}{c}526.5^{123} \\
(508.0,545.1)\end{array}$ & $\begin{array}{c}1626.1 \\
(1570.4,1681.8)\end{array}$ \\
\hline In-Season 6 & $\begin{array}{c}437.8^{123} \\
(420.0,455.6)\end{array}$ & $\begin{array}{c}409.0^{13} \\
(393.6,424.4)\end{array}$ & $\begin{array}{c}298.7^{123} \\
(286.8,310.5)\end{array}$ & $\begin{array}{c}\mathbf{5 1 5 . 7} \\
(483.8,547.5)\end{array}$ & $\begin{array}{c}1522.1 \\
(1477.1,1567.1)\end{array}$ \\
\hline In-Season 7 & $\begin{array}{c}467.2^{23} \\
(440.4,493.9)\end{array}$ & $\begin{array}{c}410.8^{13} \\
(388.4,433.2)\end{array}$ & $\begin{array}{c}308.7^{123} \\
(293.1,324.3)\end{array}$ & $\begin{array}{c}599.6^{123} \\
(567.4,631.8)\end{array}$ & $\begin{array}{c}1645.2^{123} \\
(1581.1,1709.3)\end{array}$ \\
\hline In-Season 8 & $\begin{array}{c}424.9^{123} \\
(410.4,439.3)\end{array}$ & $\begin{array}{c}412.5 \\
(397.7,427.4)\end{array}$ & $\begin{array}{c}325.7^{123} \\
(313.2,338.2)\end{array}$ & $\begin{array}{c}446.7^{23} \\
(433.4,459.9)\end{array}$ & $\begin{array}{c}1532.3^{123} \\
(1489.4,1575.3)\end{array}$ \\
\hline In-Season 9 & $\begin{array}{c}394.8^{1} \\
(381.2,408.3)\end{array}$ & $\begin{array}{c}392.0^{1} \\
(379.4,404.6)\end{array}$ & $\begin{array}{c}266.5^{123} \\
(254.6,278.4)\end{array}$ & $\begin{array}{c}\mathbf{5 5 5 . 7}^{123} \\
(537.1,574.3)\end{array}$ & $\begin{array}{c}1467.0 \\
(1430.0,1503.9)\end{array}$ \\
\hline In-Season 10 & $\begin{array}{c}401.0^{1} \\
(380.9,421.1)\end{array}$ & $\begin{array}{c}353.7^{12} \\
(332.1,375.2)\end{array}$ & $\begin{array}{c}315.6^{123} \\
(295.9,335.3)\end{array}$ & $\begin{array}{c}486.6^{23} \\
(454.7,518.5)\end{array}$ & $\begin{array}{c}1435.8 \\
(1377.0,1494.6)\end{array}$ \\
\hline In-Season 11 & $\begin{array}{c}381.1^{1} \\
(352.5,409.7)\end{array}$ & $\begin{array}{c}347.6^{12} \\
(325.9,369.3)\end{array}$ & $\begin{array}{c}332.6^{123} \\
(301.7,363.5)\end{array}$ & $\begin{array}{c}528.2^{123} \\
(507.2,549.1)\end{array}$ & $\begin{array}{c}1446.0^{123} \\
(1362.8,1529.1)\end{array}$ \\
\hline In-Season 12 & $\begin{array}{c}385.6^{1} \\
(369.7,401.6) \\
\end{array}$ & $\begin{array}{c}357.5^{12} \\
(344.6,370.4) \\
\end{array}$ & $\begin{array}{c}317.2^{123} \\
(302.0,332.4) \\
\end{array}$ & $\begin{array}{c}547.2^{123} \\
(526.4,568.1) \\
\end{array}$ & $\begin{array}{c}1472.5^{123} \\
(1410.9,1534.0) \\
\end{array}$ \\
\hline \# of Observations & 422 & 422 & 423 & $* 252$ & 415 \\
\hline
\end{tabular}


Table 3. Session Duration

\begin{tabular}{|c|c|c|c|}
\hline Seasonal Week & \# of Sessions & Average Duration & Maximum Duration \\
\hline Pre-Season1 & 8 & $2: 25: 42$ & $2: 49: 05$ \\
\hline Pre-Season2 & 8 & $2: 03: 20$ & $2: 20: 00$ \\
\hline Pre-Season3 & 6 & $1: 55: 00$ & $2: 05: 00$ \\
\hline In-season Tuesday & 12 & $1: 58: 19$ & $2: 05: 00$ \\
\hline In-Season Wednesday & 12 & $1: 52: 49$ & $2: 04: 33$ \\
\hline In-Season Thursday & 12 & $1: 32: 06$ & $3: 36: 00$ \\
\hline Game & 12 & $3: 19: 17$ & $3: 00$ \\
\hline
\end{tabular}

